\title{
Teacher Training Process with a Teachers Network and Design-Based Approach to Enhance Teacher Competency in Educational Innovations and Information Technology
}

\author{
Piyanee Chitcharoen, Jaitip Na-Songkhla, and Noawanit Songkram
}

\begin{abstract}
We represent ICT Training for teacher process on framework that consider teacher need in ICT teaching integration. We design and planning ICT teaching by teacher themselves with Design- Based Approach. There are teachers network for support motivation and discussion practice and recording results for reflection. Analysis differential of start and end of training show the teacher have higher ICT competency and more understand to select ICT in teaching management.
\end{abstract}

Index Terms-Teacher training, information and communication technology (ICT), teacher competency, teachers network, design-based approach.

\section{INTRODUCTION}

Ministry of Education specify teacher and related persons competency development system by innovative and educational technology competency are key competency in self development [1]. Because ICT become important tool for learning, teacher must have knowledge to use tool that leading to efficient lifelong learning. Which most of innovative and educational technology competency development methods use large group training methods? If trainee had lack of motivation in training, training would not successful and no actual implementation. Therefore, Encouraging teachers to collaborate, promoting the knowledge sharing and practicality is another way to develop self-competency according to their needs and suitability of individuals by promoting the knowledge creation process in order to solve the problem from actual conditions in teaching, motivation and goal setting to succeed, technology applied in teaching with understanding and flexible. In order to use technology as proper tool and create a teachers network through an online social network, in cooperation with common target setting in teachers network to develop trained teachers in knowledge sharing problem and experiences in teaching, to be performed continuously in the their own actual working environment and to create a sustainable knowledge sharing community [2].

Manuscript received April 5, 2014; revised June 20, 2014.

The authors are with the Department of Educational Technology and Communications, Faculty of Education, Chulalongkorn University, Bangkok, Thailand (e-mail: pinaclepin@hotmail.com, jaitipn@gmail.com, noawanit_s@hotmail.com).

\section{THEORETICAL BACKGROUND}

\section{A. Design-Based Approach}

The design-based approach [3], [4] (see Fig. 1) is commonly linked to research into computer-based technologies and the learning environments they afford, culminating in the creation of products to be used in solving identified problems. While it is anticipated that using such technologies to support learning will feature in the findings, this study's focus is to develop self-competency according to their needs and suitability of individuals by promoting the knowledge creation process in order to solve the problem from actual conditions in teaching practicality. Anfara and Mertz [5] argue that looking beyond one's own field of expertise to consider the theoretical frameworks of others can provide fresh perspectives and new understandings about a theoretical problem. It is with this focus on the development of guiding principles along with the opportunity to make links between classroom practice and learning theories that design based research was selected as an appropriate overall approach for this study [6]. Such as Joseph [7] identifies the three goals of design-based research as 'research, design and pedagogical practice'.

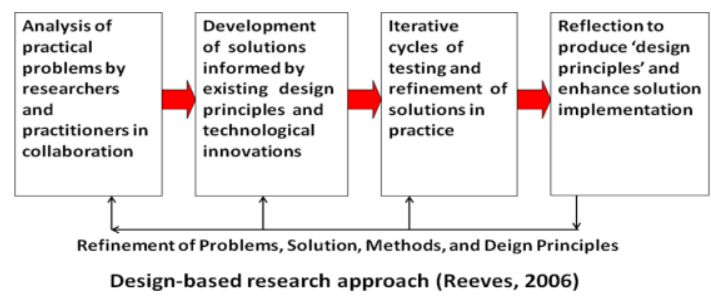

Fig. 1. Design-based approach (Reeves, 2006).

\section{B. Teachers Network}

Networked learning is a process of developing and maintaining connections with people and information, and communicating in such a way so as to support one another's learning. The central term in this definition is connections. It takes a relational stance in which learning takes place both in relation to others and in relation to learning resources [8]. It has been suggested that networked learning offers educational institutions more functional efficiency, in that the curriculum can be more tightly managed centrally, or in the case of vocational learning, it can reduce costs to employers and tax payers. However, it is also argued that networked learning is too often considered within the presumption of institutionalised or educationalised learning, thereby omitting awareness of the benefits that networked learning 
has to informal or situated learning [9].

\section{Goal Setting Theory}

The Goal Setting Theory was developed by Edwin A. Locke in 1968, in order to explain human actions in specific work situations. The theory argues that goals and intentions are cognitive and willful, and that they serve as mediators of human actions and that our needs and our goals are mediated by our values, which determine what is beneficial for us.

The two most important findings of this theory are that setting specific goals (e.g., I want to earn \$500 more a month) generates higher levels of performance than setting general goals (e.g., I want to earn more money), and that goals that are hard to achieve are linearly and positively connected to performance. The harder the goal, the more a person will work to reach it. However, such influences on performance are mediated by two conditions - feedback, and that the person in question accepts the goal [10].

A goal is described as reaching a great certain level of efficiency in a certain area, usually under a time limit. Goals have two characteristics - the goal's content, and the goal's intensity. The content refers to what we actually want to achieve (e.g., I want to earn $\$ 500$ more a month). The intensity refers to the amount of physical and mental resources needed to create and achieve the content. The original model proposed by Locke consisted of five steps: Environmental Stimuli $\rightarrow$ Cognition $\rightarrow$ Evaluation $\rightarrow$ Intentions/ Goal Setting $\rightarrow$ Performance [11].

To enhance teacher competency in educational innovation and information technology. Teacher training process compound by Design-based approach, Teachers network and Goal Setting Theory as show in Fig. 2.

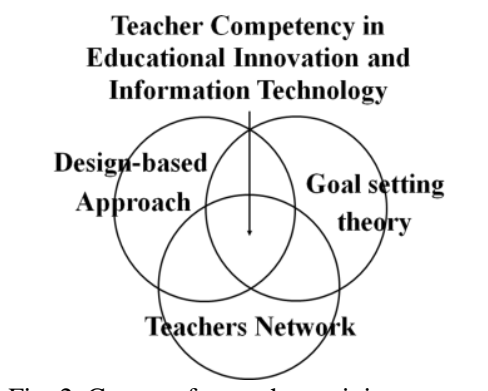

Fig. 2. Concept for teacher training process.

\section{PuRPOSE OF THE RESEARCH}

1) To development a teacher training process with a teachers network and Design-based approach to enhance teacher competency in educational innovation and information technology.

2) To study the results of teacher training process with a teachers network and Design-based approach to enhance teacher competency in educational innovation and information technology.

\section{SCOPE OF THE RESEARCH}

\section{A. Population}

1) Teachers in fundamental education level

2) Experts information Technology, Teacher ICT Training,
Knowledge Management and Educational Administration.

\section{B. Sample Groups}

1) Teachers in fundamental education level 2 groups each group has 15 persons one for model development and another for tryout model; all of them selected by purposive sampling for study the results of teacher training process with a teacher network and Design-based approach to enhance teacher competency in educational innovation and information technology.

2) Experts information Technology, Teacher ICT Training, Knowledge Management and Educational Administration 7 persons for the interview comments.

\section{Variables of the Research}

Independent variable is a teacher training process with a teachers network and design-based approach to enhance teacher competency in educational innovations and information technology.

\section{Research Design}

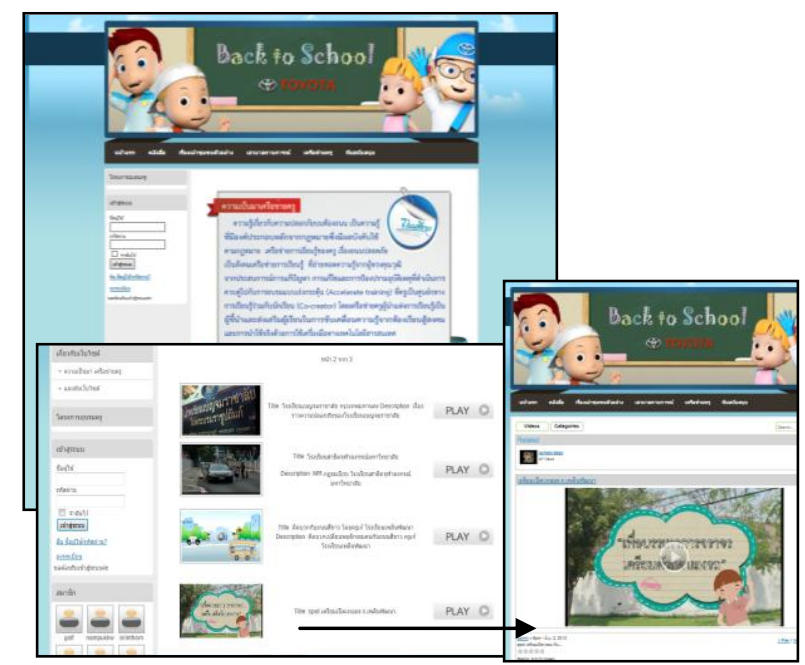

Fig. 3. Website for teacher training process.

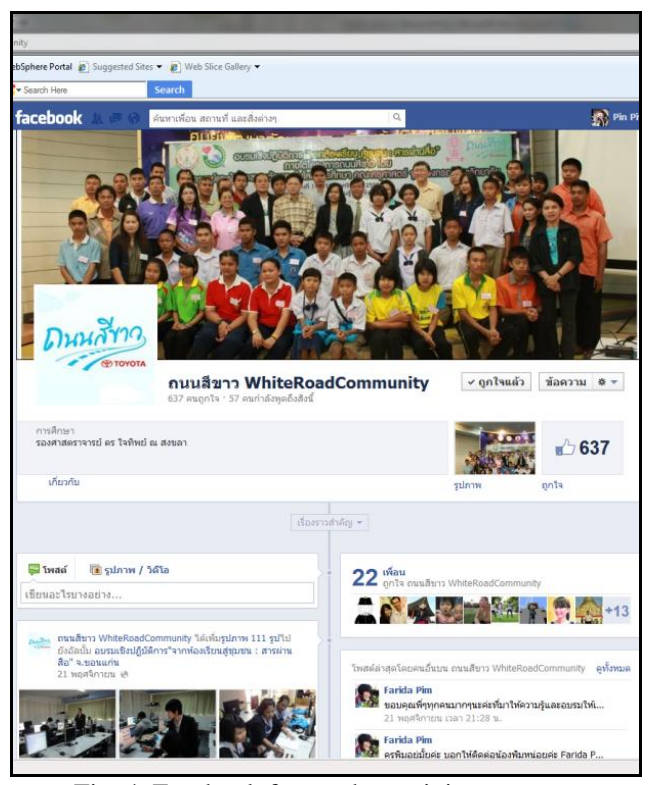

Fig. 4. Facebook for teacher training process.

The teacher training process was integrated with 4 phase of activities in 9 weeks. Each phase has activities for training 
purposes including analysis of practical problems, training to use ICT tool and Write ICT integration lesson plan for develop teacher competency in educational innovation and information technology (see Fig. 3 and Fig. 4).

\section{Methodology}

This paper purpose a teacher training process with a teachers network and Design-based approach to enhance teacher competency in educational innovation and information technology that use Design-based approach and teacher network to enhance teacher competency in educational innovation and information technology.

Phase 1: To study factors that support the teacher training process with a teacher network and design-based approach to enhance teacher competency in educational innovation and information technology.

1) Study, analyze and synthesize documents and formerresearches relevant to the teacher network, design-based approach, teacher competency in educational innovation and information technology.

2) Send questionnaire to sample groups and wait for responsed, analyze and synthesize data in questionnaire.

Phase 2: The development of teacher training process with a teachers network and Design-based approach to enhance teacher competency in educational innovation and information technology Model. Model was shown in Figure 5 .

1) Create the first model(1) that the model is developed based on the data obtained from the research study used in the formulation of the model development concept.

2) Presented to thesis advisor and co-advisor for Consideration and modified it as guided.

3) Trial the first Model(1) to group similar sample groups.

4) Data collection, analysis and develop the first $\operatorname{Model}(1)$ to the second Model(2).

5) Bring the second $\operatorname{Model}(2)$ to trial with the sample groups.Data collection and analysis.

6) Send to thesis advisor and co-advisor for consideration. Analysis and develop the second $\operatorname{Model}(2)$ to the third Model(3).

7) Send to the experts for review and evaluates.

8) Modified according to the experts' suggestions.

9) Presenting the third $\operatorname{Model}(3)$ in the form of diagram with report.

10) Analyze the results of evaluation of the factor by percent, and the model by Index of Item Objective Congruence (I.O.C)

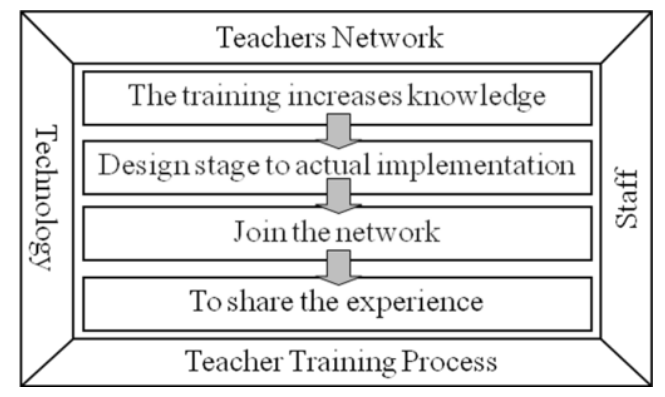

Fig. 5. The development of a teacher training.
Phase 3: The study of teacher training process with a teachers network and design-based approach to enhance teacher competency in educational innovation and information technology Model. (See Figure.6)

1) Preparation to study the effects of the training process, created a tool used in the research including performance assessment of educational innovation and technology, after action review (AAR), performance assessment of ICT integrated lesson plans.

2) Data collection and analysis of recommendation from experts

3) Send the certification form to the experts for review and evaluates.

4) Data collection and analyzed by the average and standard deviation Then the data was analyzed by summarizing the feedback issues and presented in the form of commentary.

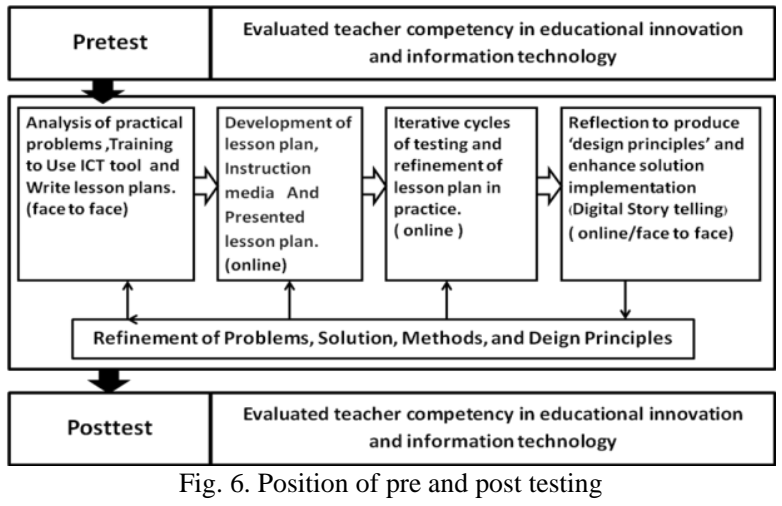

Phase 4: Presenting the teacher training process with a teachers network and design-based approach to enhance teacher competency in educational innovation and information technology Model.

1) Certification the training process.

- Certify the training process.

a) Assign experts for certification training process.

b) Create tools for certification training process. The following issues is 1) composition, 2) Step 3) theoretical principles involved.4.) the training process 5) Implements the training process to practice

- Presented to thesis advisor and co-advisor for consideration and modified it as guided.

- Collect and analyze data from the training certification process.

a) Bring the certification training process to certify qualified

b) Collect data from a certified training process states. A certification by the quantitative data from the analysis of the mean and standard deviation then the data was analyzed by summarizing the feedback issues and presented in the form of commentary.

2) Presentation training process

- Bring suggestions and comments received from the experts with data and the findings of the study of the training process to a conclusion. Then revised training process developed to ensure accurate and complete as possible.

- Proposed training process In the descriptive and diagrams to be used as a guideline in development of 
teacher training process with a teachers network and Design-based approach to enhance teacher competency in educational innovation and information technology.

\section{RESULT}

We found that using a Design-based approach on teachers network make the teachers have brought knowledge from ICT training to use on a daily basis because they select problems from actual teaching and discover the problem solving in self-operation, able to write lesson plans which integrated technology to effective teaching and learning. In addition, the teachers network to help boost support, teachers get help and exchange experiences with fellow teachers in the network, consultation, exchange ideas, teachers can well improvement their ICT skills. Preparation for teachers who want to develop their own performance in terms of innovation and educational ICT should be manage processes and procedures commensurate with the nature of the problem, and working of regular teacher, so the teacher will be developed based on authentic needs. As noted by Anderson [12] 'design-based research does not seek for universal solutions but rather for deep understanding of innovations and the factors those effect improvement in local contexts'. There are exercises in everyday life as well as the flexibility to select and manage the teaching and learning of their own courses. It promotes the network teacher for collaborative learning, experience exchanging between teachers in order to encourage collaborative working to achieve their own goals and community goal.

\section{REFERENCES}

[1] The National Institute for the Development of Teachers, Faculty and Staff and Education Personnel, "Strategic development of teachers and educational personnel (2006-2008)," Office of the Permanent Secretary, Ministry of Education, 2005.

[2] The committee of education reform, "Strategic Plan for education reform (2005-2008)," Ministry of Education, 2005.

[3] T. C. Reeves, "Design research from a technology perspective," in J. V. D. Akker, K. Gravemeijer, S. McKenney, and N. Nieveen (Eds.), Educational design research, UK: Routledge, 2006, pp. 52-66.

[4] J. van den Akker, K. Gravemeijer, S. McKenny, and N. Nieveen, Educational design research, Oxon: Routledge, 2006.
[5] V. A. Anfara and N. T. Mertz, Theoretical frameworks in qualitative research, Cal: Sage, 2006.

[6] K. Akker et al., "Using design principles to improve pedagogical practice and promote student engagement," presented at the conference on ascilite 2011, pp. 594-601.

[7] D. Joseph, "The practice of design-based research: Uncovering the interplay between design, research, and the real-world context," Educational Psychologist, vol. 39, no. 4, pp. 235-242, 2004.

[8] L. Dirckinck-Holmfeld, C. Jones, and B. Lindström, Analysing Networked Learning Practices in Higher Education and Continuing Professional Development, Rotterdam: Sense Publishers, BV, 2009.

[9] S. Fox, "Studying networked learning," in Networked learning: perspectives and issues, C. Steeples, C. Jones ed., London: Springer, 2002, chapter 5 .

[10] E. A. Locke and G. P. Latham, A Theory of Goal Setting and Task Performance, Englewood Cliffs, NJ: Prentice-Hall, 1990.

[11] E. A. Locke and G. P. Latham, "Building a practically useful theory of goal setting and task motivation: A 35-year odyssey," American Psychologist, vol. 57, pp. 705-717, 2002.

[12] T. Anderson, "Design-based research and its application to a call centre innovation in distance education," Canadian Journal of Learning and Technology, vol. 31, no. 2. 2005

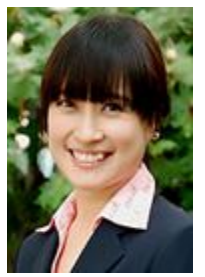

Piyanee Chitcharoen is a Ph.D. candidate at education technology from Chulalongkorn University, Thailand. Her major research interests include the teacher training, teachers network and teacher competency in educationa innovation and information technology. She spent several years teaching career and technology education in Chulalongkorn University demonstration elementary school.

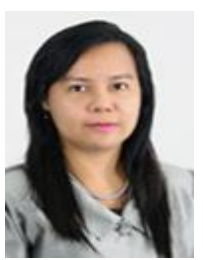

Jaitip Na-Songkhla is an associate professor of the Department of Education Technology, Education Faculty, Chulalongkorn University, Bangkok, Thailand.

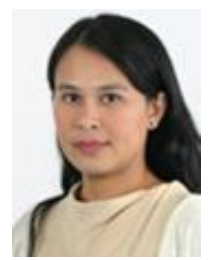

Noawanit Songkram is an associate professor of the Department of Education Technology, Education Faculty, Chulalongkorn University, Bangkok, Thailand. 